\title{
Uncommon cause of obstruction in the left ventricular outflow tract by a metastasis of adenocarcinoma
}

David Zemanek ${ }^{1}$, Josef Veselka1 ${ }^{1}$ Teodor Adla², Marek Setina ${ }^{3}$, Jiri Ferda ${ }^{4}$

1Department of Cardiology, University Hospital Motol, $1^{\text {st }}$ Medical School of Charles University, Prague, Czech Republic

2Department of Imaging Methods, University Hospital Motol, 2nd Medical School of Charles University, Prague, Czech Republic

${ }^{3}$ Department of Cardiac Surgery, University Hospital Motol, 2nd Medical School of Charles University, Prague, Czech Republic

${ }^{4}$ Radiodiagnostic Clinic, Charles University Teaching Hospital, Prague, Czech Republic

Submitted: 23 August 2009

Accepted: 16 October 2010

Arch Med Sci 2010; 6, 6: 981-983

DOI: 10.5114/aoms.2010.19313

Copyright (c) 2010 Termedia \& Banach

\section{Abstract}

Cardiac metastases are rare diagnoses among cardiac disorders. This case demonstrates a unique presence of an obstruction in the left ventricular outflow tract caused by the metastasis of a renal carcinoma. Adequate diagnostic and therapeutic procedures were lifesaving in this potentially fatal diagnosis.

Key words: left ventricular obstruction, cardiac metastasis

\section{Introduction}

An obstruction in the left ventricular outflow tract (LVOT) is observed mainly in patients with a hypertrophic cardiomyopathy. It is rarely seen in other diagnoses, such as fibromuscular subvalvular aortic stenosis, another extremely rare congenital heart disease, and tumours. All these diagnoses comprise less than $1 \%$ of cases of LVOT obstruction.

\section{Case report}

A 60-year-old male was admitted to a cardiology department for presyncope and dyspnoea. The electrocardiogram revealed a sinus rhythm and a right bundle branch block without any other changes. Transthoracic echocardiography showed a non-dilated left ventricle with a normal ejection fraction. The basal septum was slightly thickened $(15 \mathrm{~mm})$ without a significant rest obstruction in LVOT, but with slightly increased flow velocity in LVOT and intimated systolic anterior motion of the anterior mitral leaflet. Exercise echocardiography revealed the obstruction in LVOT (maximal pressure gradient was $51 \mathrm{mmHg}$ ), together with a systolic anterior motion of the anterior mitral leaflet at peak exercise (Figure 1A), and explained the patient's symptoms. The coronary angiography showed both a significant stenosis of the left anterior descending artery, and a blush formation in the upper interventricular septum (Figure 1B). We considered performing real-time myocardial contrast echocardiography with selective application of contrast agent to the septal branch, but rejected this due to its invasive character [1]. To evaluate this hypervascularized mass,

\author{
Corresponding author: \\ David Zemanek, MD \\ Department of Cardiology \\ University Hospital Motol \\ 1st Medical School \\ of Charles University \\ K Cervnemu vrchu 844/2a \\ 16000 Prague, Czech Republic \\ E-mail: zejada@seznam.cz
}




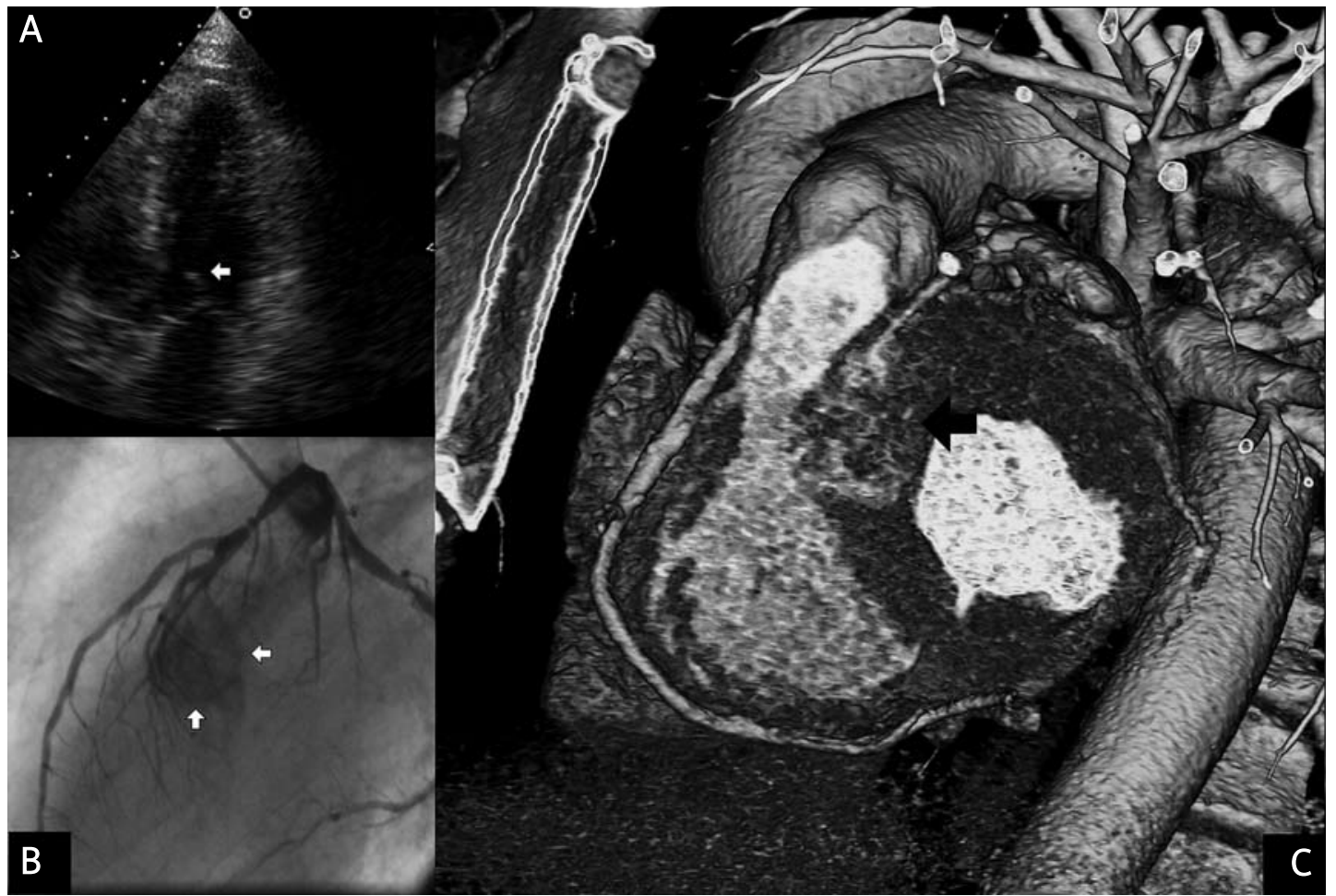

Figure 1. A - Transthoracic echocardiography, systolic anterior motion of anterior mitral leaflet - arrow, B - Coronary angiography, blush formation - arrow, C - Computed tomography - three-dimensional reconstruction, hypervascularized mass - arrow

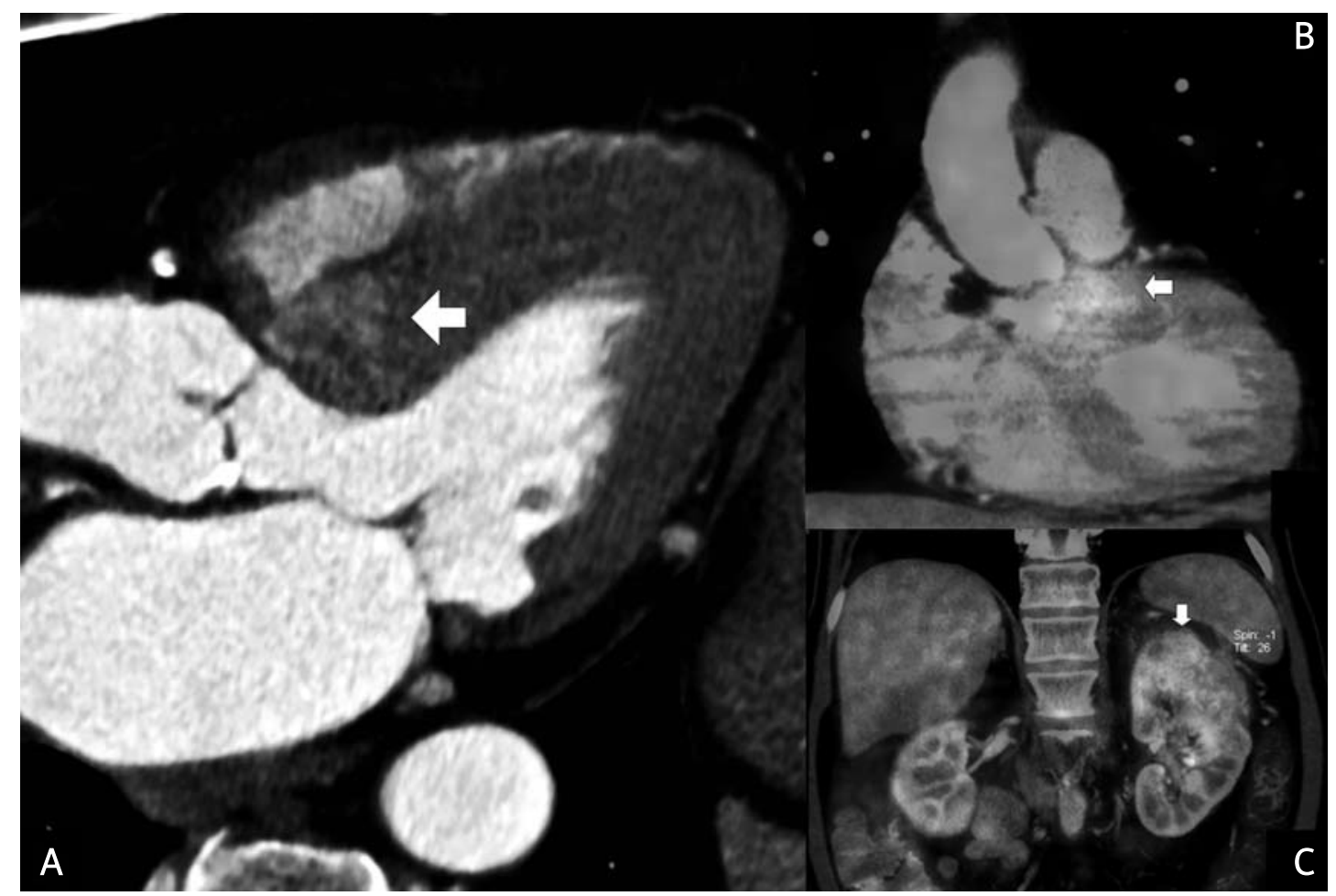

Figure 2. A - Computed tomography, hypervascularized mass - arrow, B - Positron emission tomography/computed tomography, metastasis into ventricular septum with increased 18-F-FDG metabolism - arrow, C - Positron emission tomography/computed tomography, primary renal adenocarcinoma with increased 18-F-FDG metabolism - arrow 
the patient underwent cardiac computed tomography $(\mathrm{CT})$, where a heterogeneous contrast-accumulating intraseptal formation $(2.5 \times 2.2 \times 3.0 \mathrm{~cm})$ with rapid enhancement suspected to be a neoplasm (Figures 1C, 2A) was found. Cardiovascular magnetic resonance imaging did not bring any profitable accessory information. Considering the fact that primary intramural cardiac tumours are very rare, we decided to perform whole-body $18-\mathrm{F}-$ FDG-positron emission tomography (PET)/CT. There was a renal cell carcinoma found with metastases into the ventricular septum and retroperitoneal lymphatic nodes (Figures 2B, C). The patient underwent a nephrectomy with lymphadenectomy. Subsequently, a successful resection of the basal part of the interventricular septum with a prosthetic patch and an arterial bypass to the left anterior descending artery were performed and the patient was discharged from hospital after three weeks. The patient is still alive half a year after the surgery.

\section{Discussion}

Whereas cardiac tumours are rare, we found only a few cases with tumour obstruction of the LVOT while searching the literature. Most of them primarily involved the left atrium, and prolapsed into the left ventricle, causing obstruction, or involved the left ventricle cavity and were mobile [2]. Japanese authors described a similar case, where the obstruction of the LVOT was caused by interventricular involvement by the metastasis of a lung adenocarcinoma [3]. However, the involvement of the left ventricular myocardium was more advanced $(35 \times 45 \times 35 \mathrm{~mm})$, and the patient died a short time after the diagnosis.

This case is a challenging report of an obstruction in the LVOT caused by an intraseptal cardiac metastasis of adenocarcinoma detected by exercise echocardiography and diagnosed by $\mathrm{PET} / \mathrm{CT}$. It also demonstrates that modern imaging methods along with adequate diagnostic and therapeutic procedures can be life-saving in some potentially fatal diagnoses.

\section{References}

1. Veselka J, Zemanek D, Fiedler J, Svab P. Real-time myocardial contrast echocardiography for echo-guided alcohol septal ablation. Arch Med Sci 2009; 5: 271-2.

2. Coller JM, Parente P, Esmore D, New G, Murugasu A, Cooke JC. Large left ventricular metastasis causing left ventricular outflow tract obstruction and haemolysis. Eur J Echocardiogr 2009; 10: 456-8.

3. Kasai T, Kishi K, Kawabata M, Narui K, Momomura S, Yoshimura K. Cardiac metastasis from lung adenocarcinoma causing atrioventricular block and left ventricular outflow tract obstruction. Chest 2007; 131: 1569-72. 